\title{
"You helped us and now we're going to all help you": What we learned about how to do research together
}

\begin{tabular}{|c|c|}
\hline $\begin{array}{c}\text { Lisa Hall } \\
\text { Batchelor Institute } \\
\text { lisa.hal/@batchelor.edu.au }\end{array}$ & $\begin{array}{c}\text { Linda Anderson } \\
\text { Papunya Community }\end{array}$ \\
\hline Fiona Gibson & Mona Kantawara \\
\hline Nyirrpi Community & Ntaria Community \\
\hline Barbara Martin & Yamurna Oldfield \\
\hline Yuendumu Community & Yuendumu Community \\
\hline
\end{tabular}

Keywords: research, conversation, ethics, reciprocity, relationships, dialogue, consent

\begin{abstract}
This paper is a critically reflective "think piece" that explores a collaborative process of doing research in an intercultural space as well as identifying what focusing on such a process produces. While it originates from a PhD project centred on the concern for the low number of people becoming qualified as teachers from remote Aboriginal communities in central Australia, this paper does not directly discuss that topic. Instead it discusses how a non-Indigenous researcher (Lisa) worked with a group of fully qualified Aboriginal teachers (including Linda, Fiona, Mona, Barbara and Yamurna) to explore this common concern. The focus here is on the collective processes we used in doing the work together, and how that ensured that the research happened ethically and relationally, such that everyone was left with a "good feeling" at the end of the work. This paper talks about the conversational or dialogic approach we took in our work together and how we discovered the paths that felt "right" for the research to take. It contains some examples of our conversations that we recorded throughout the research process and names some of the things that made the work we were doing together feel "right". Together we discovered new knowledge about how we communicated with each other, what true informed consent looked and felt like for everyone involved, the central importance of our existing relationships, and the role of reciprocity in intercultural research.
\end{abstract}

\section{Introduction}

This paper is attempting to draw attention to two things: first, a process of working together in an intercultural setting; and, second, a reflection of what focusing on process produces, how this works and what it does both for the present and the future. This paper grew out of a series of oral conversations that were built into a $\mathrm{PhD}$ research process involving a nonIndigenous researcher and a number of Aboriginal teacher participants. We had pre-existing professional and personal relationships before this research began. The idea for the research came from the previous work we had undertaken and the conversations about the research began well before the actual research did. Because the research began as conversation, and 
out of a philosophical orientation that placed value on protecting and maintaining our existing relationships, we deliberately built ongoing intentional conversations into the research design. This conversational approach, based on strong evidence relating to Indigenous research paradigms, was designed to ensure relational and ethical accountability between the researcher and the research participants as the research process continued. What we discovered was that these conversations and our reflections became an iterative process enabling us to learn as we went about the best way to do this research together. Together we discovered new knowledge about how we communicated with each other, what true informed consent looked and felt like for everyone involved, the central importance of our existing relationships, and the role of reciprocity in intercultural research. By the end of the work, as we discussed what we had done with a wider group of people, we realised that this design provided an excellent road map for the kind of process that supports good intercultural work to occur. We decided to write this paper to share what we learned with others so that they might be able to reflect on and adapt their own practice. We also hope that our findings might help to develop better policies about doing intercultural research.

\section{Background and context}

In 2011 Lisa, who is non-Indigenous, enrolled to do her PhD. This decision came after a long period of working with a group of Aboriginal teachers from remote communities in central Australia. This group of teachers included Linda (from Papunya), Fiona (from Nyirripi), Mona (from Ntaria/Hermannsburg), and Barbara and Yamurna (from Yuendumu).

Figure 1: Map of central Australia; blue stars mark the co-authors' communities.

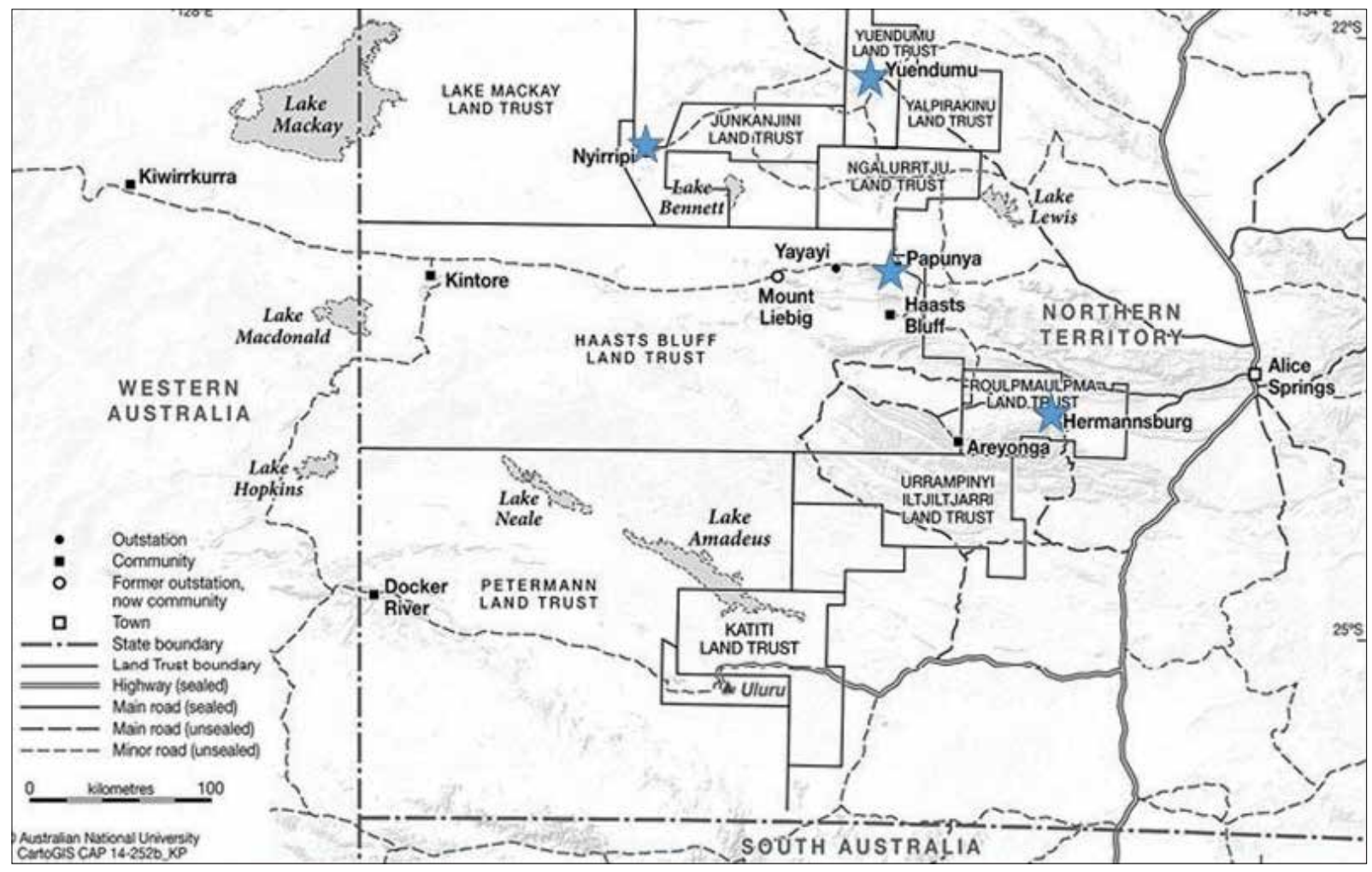

Source: Karina Pelling, CartoGIS, ANU College of Asia and the Pacific 
In our original work together, Lisa was a lecturer supporting the teachers to complete a 4th year qualification in teaching. During that period of working together it became clear that all of us shared a very real and passionate "common concern" (Addelson, 1994) for the low number of people becoming qualified as teachers from the respective communities where the teachers lived and worked. We talked about this issue a lot and wanted to explore it further. After a great deal of discussion we decided that Lisa could focus on it as a PhD project (Hall, 2016). All of the teachers would work with her to explore this common concern by sharing their stories of how they became teachers then, all together, deciding what important knowledge and ideas we could learn from these stories. As the project started from our existing relationships this presented some interesting paths to navigate in the research landscape, including resistance by western ethic committees who are frequently sceptical of relational research because of a perceived "potential to bias" (Kovach, 2010, p. 42) This research, which was inherently intercultural, had to walk along a line of tension between an Indigenous paradigm and western qualitative research. What helped us to walk this line was a sense of clarity about our "philosophical orientation" (Kovach, 2010, p. 41). In our pre-research conversations this was expressed simply as wanting everyone to be left with a "good feeling" at the end of the research. Helen Verran (2013) talks similarly about the need to work together in "good faith". To this end we took a conversational or dialogic approach in our work together. Kovach (2010) explains the conversational method as a "method of gathering knowledge based on oral story telling tradition....It involves a dialogic participation that holds a deep purpose of sharing story as a means to assist others. It is relational at its core" (Kovach, 2010, p. 40). Some of this method was pre-planned and built into the early stages of the research, where a long "conversational phase" of over a year was factored in. However, we also realized the need to continue in conversation with one another throughout the entire process and these conversations were "dialogic, relational and reflective" (Kovach, 2010, p. 46). This open and honest dialogue was an important aspect of working together ethically. As Kovach (2010) points out, taking a conversational approach enables an inter-relationship between the method, ethics and care within the research. In this dialogue we were able to observe, identify and name some of the things that made the work we were doing together feel "right". Together we discovered new knowledge about communication, true informed consent, relationships and reciprocity. This paper includes sections of our recorded conversations that illustrate what we learned together as we undertook this research work.

\section{The collaborative research process}

Throughout the almost five years of working together on this research we moved flexibly back and forth between story and dialogue as we discovered the paths that felt "right" for the research to take. Sometimes this occurred in the negotiation of the data collection, at other times this was done one-to-one, as part of the story telling sessions. There were times when the conversation involved everyone, for example when we came back together to do the analysis work. We took the time to talk together at different stages of the research process. At those times we shared ideas about how to work together as well as talking about how we were feeling about our participation as the work was happening. These ongoing and intentional conversations throughout the research process provided what Verran (2013) calls "interrupting tools". Verran talks about the need to pay attention to moments of epistemic disconcertment and to be alert to the differences we encounter. These intentional conversations about the research process helped us to "go deeper inside the encounter" (Verran, 2013, p. 147) to explore how the way we did things actually helped us to work in "good faith" with each other. There were a number of specific choices we made about how to undertake the various stages of this research together that were important. Those stages are outlined below. 
1) A long conversational phase at the beginning of the research enabled Lisa and the teachers to have extended discussions, enough thinking time and time to ask questions about the research process before any of the stories were recorded. Central to this was a two-hour group discussion in November 2013 about the project where almost all of the teacher participants were present, including the five co-authors of this paper and two other teacher participants. This conversation was recorded and transcribed with people's consent and permission. This led to a number of ad hoc group and individual conversations taking place over the following months which were not recorded or transcribed but many of which were included in Lisa's reflections in her research notes. No narrative recording sessions commenced until each teacher indicated their readiness to begin. The first of the narrative recordings began in January 2014.

2) At the end of each narrative recording, Lisa and the teacher she was working with had a final reflective conversation. The focus of this conversation was to document how both people were feeling about the research process so far. In each instance it was a moment of ethical and relational accountability to each other, to ensure that the consent given at the beginning of the process still felt true for both people. These conversations were recorded on audio only and transcribed, again with full consent.

3) After all the narratives had been recorded, we came back together to analyse the collective stories and to decide together on the important ideas contained within them. We also talked about what kind of research outcomes and dissemination processes might work best to share the stories more widely.

The conversations during these three specific stages were recorded and then transcribed. When we looked at the transcripts of those conversations they showed us that certain things were important in helping us to work ethically together. Those things were ongoing communication, finding a way to establish true ethical consent, relationships and reciprocity. Each of these four areas will be discussed in the findings and discussion section below, along with examples from our conversations related to those ideas.

\section{Findings and discussion}

\section{Communication: Intentional conversations and staying in touch}

One of the things that really helped us to work together on this project over a period of more than five years was our ability to keep the lines of communication open. This was done in both intentional and iterative ways. When we looked at the transcriptions of the intentional conversations that we had, we realised that good communication - both planned and spontaneous - made a real difference to people wanting to keep going with the research.

As stated previously we had an intentionally long "conversational phase" at the beginning of the research. This allowed us more than a year before any recordings were made to discuss the research design, participation, consent and the process for data collection. This phase included one intentional conversation altogether as a group that took place at Batchelor Institute Top End campus (south of Darwin in the Northern Territory) in 2013. During this conversation a number of people talked about the importance of talking about things before starting them, to give people time to consider and understand. For example, Linda said, "and it's alright that you've come today, you know to let us think about it...just have it in our minds".

This group conversation was followed by a number of individual follow-up conversations to check in about when would be a good time to start the process with each person. Very often the conversational phase also included, where possible, a conversation on country with Elders 
and leaders in the respective communities. These conversations took place to explain the research we were doing together and to invite input from the Elders. These conversations were not recorded or transcribed, but helped shape the way that we conducted the research as well as informing our later discussions about dissemination of the research.

After these intentional conversations that helped in the research design process, staying in touch and communication were very important. They were especially important during the time before each of the teachers sat down to record their story with Lisa. The following conversation between Lisa and Fiona reflects on this.

Lisa: I've seen you a lot during the year and you've been saying to me "don't worry I won't forget about you!"

Fiona: Yuwayi (yes) (laughs), I won't forget about you. Because you know those problems that I had... my health problems, but I was still thinking "Oh I'm gonna do something with Nampijinpa (Lisa)".

Lisa: That was good for me because you were really good at communicating to me that you still wanted to do it...you still wanted to participate in the research, but that you would let me know when it was a good time, when it was the right time for you.

Fiona: Yeah.

Lisa: So how did you work that out for yourself? What were you thinking about in terms of when you were ready?

Fiona: Because like lot of appointments was coming and I had to be on that dialysis like three times a week and that made me feel really like worried about "when can I help Nampijinpa (Lisa)?" and then I thought to myself I'll just text message her and we might work out the dates, like after Christmas, you know like after New Year's. I think that's a good time. And like days when I don't have dialysis, Monday Wednesday, Friday, Sunday is good.

Another example is this excerpt from a conversation between Yamurna and Lisa reflecting on how we had gone about the process of organising the recording her story,

Lisa: Have you been happy with how we've done it so far with me coming out here and sitting down together?

Yamurna: Yep, (you're) not like catching me in the street, it's good sitting down, just doing your work here and telling me, reading questions and you know telling me, it's really good... it's been really good because you've been sending messages, telling me that you're coming and I'm ready. See I was going to go hunting today but I stopped. I usually go hunting on Saturday (both laugh).

Lisa: Oh I feel bad now that I stopped you!

Yamurna: No lawa (no/nothing), I didn't plan for going hunting. I knew that you were coming. 
One of the things that was helpful in keeping the communication open was Lisa's previous experience working with Aboriginal people for many years. For example, Mona said this to Lisa when they were reflecting on how they were feeling at the end of recording Mona's story:

I think you weren't pushy. You weren't ringing me up all the time "oh when are you going to do it". I think it was the right time... how can I put it, you thought of the right time as well. Yeah 'cos one time you emailed me for something and said "when is that thing gonna happen?" and I think you're good at understanding, yeah really good l'd say. 'Cos you know, if I said "no it's not a good time 'cos I got problem", something came up with the boys or something you know or I wasn't well, I think you're really good at that, you know "oh kala (ok), leave it". I think you learned a lot about Indigenous culture and that really helped, helps you and me, you know, to understand each other. Yeah, you're not (saying) "I'm coming this week, be ready!" you know. And I think time (and) space was good, you know we talked about it and then you know you got in touch, emailed me and said "is it a good time?" Just getting in touch with someone.

Thrift (2004) talks about having knowledge, experience and relationships with people with whom you are working as being essential for enabling "ethical encounters". He sees this as being part of the real ethics of doing research and suggests that things such as "knowing when to wait for a response, knowing when and when not to foreclose a situation, knowing when to be playful and when to be serious...can open out the ethical possibilities of an encounter and allow both the researcher and the researched to trust their judgement" (Thrift, 2004, p. 120). Finding ways to communicate with each other that are respectful and flexible helped us to keep talking to each other about the work we needed to do. This involved regular checking in ways that weren't pushy or forced, but instead invited an ongoing conversation about discerning the right time for people to work together.

\section{Genuine informed consent: Looking for the right time, waiting until l'm ready}

One of the most important aspects of allowing lots of time for conversation before the research itself started was that it offered an important opportunity to explain the research process slowly and also helped people understand the concept of informed consent. In addition to Lisa being able to explain things from the university side, it also offered everyone the chance to talk about a preferred way of operating. This is highlighted by the following extract from the group conversation we had together in 2013 about consent,

Lisa: (and) even if you say yes at the beginning you need to understand you can say no to me again, if things get hard, if you have sorry business... if something gets hard in your life and you don't have time anymore, you can say no at any point down the track. Yeah? Just because you say yes to me at the beginning, doesn't mean you have to keep going, keep going, keep going. You can still say no and it's important that you understand that.

Mona: Not usually, you know straight answer "no" but you know, "give me time".

Barbara: Yeah, "I'll think about it".

Lisa: Also, you might have some worries along the way. I might have come out and you might have talked about something and you might be thinking about it and think "Oh I shouldn't have said that" or "I should have said this other thing, I'm just 
thinking about that now"...but instead of worrying about it then just tell me about it, talk to me about it...you can say to me, "oh Lisa l've been thinking about this a lot and I'm a bit worried about this" and then we can talk about it and find a solution together.

Linda: Talk about it, yeah.

Lisa: ...l'd like it so that no one gets to the point where they think "Oh I'm so worried about it I'm gonna drop out", you know?

Linda: ...talk about you know if you're not happy with that, find another way of explaining.

In our work together we didn't treat consent as a one-off thing that we did at the beginning of the research. Our attitude to informed consent was that it was something we had to co-create. We needed to keep checking in with each other throughout the process to see if it still felt true and to find out if people still felt like they could freely participate in what we were doing together. This perhaps points towards a point of difference in relation to ethics which can be identified and consent granted into the future through western metaphysics, but in Indigenous knowledge and understandings it is always provisional as reality itself emerges (explored in greater detail in Hall, 2017). In a conversation between Lisa and Fiona at the end of recording her story, Fiona reflected on the importance of planning the research together as something that supported her to participate.

Lisa: How have you felt about how l've done things as a researcher? Have I done my job alright?

Fiona: I think we planned it really well. I gave my plan to you, I told you don't worry I'll give you a date, what date we can work when l'm ready. I was text messaging you, you know. And so that way we can like have a good talk...but you never forced me, you didn't tell me what to do. You only asked me questions, you showed me the questions in the paper, and l've answered those questions, I did the right thing, the right thing for you, the right questions that I've answered back. We talked about the papers that you showed me and I signed it. Yuwai (yes) that was really good that we shared, you asked me a lot of good questions.

The fact that Fiona kept saying she would let Lisa know when she was ready indicated that she was thinking about her participation and making conscious choices about the right time to start. Lisa had to trust in her relationship with Fiona that she would identify the right time to move forward with her participation in the research.

A similar experience was articulated by Barbara in conversation with Lisa. When asked about how she had found the research process, Barbara said,

Barbara: My only worry that I had was this is the end of year now and all the time I haven't come in and talk(ed) to you, we left it for last minute, you know for very long time, and I felt deeply in my heart I felt guilty, you know. All the time (I was thinking) I need to sit down with Pitjan (Lisa), yuwa (yes), I need to sit down. I didn't forget you, I kept thinking about you and your project, $P h D$... 
Lisa: I always knew that you wouldn't leave me without finishing it off. And we have talked about it a few times...you were very good at coming back to me and saying "when are we going to finish that work, when are we going to finish that work?"

Barbara: And ringing you.

Lisa: And we just had to wait for the right time I felt... I think part of it is, you're busy, you've got a lot of things going on in your life and some stresses and some worries.

Barbara: Yuwa (yes).

Lisa: I'm busy, l've got work full time too, and so we can't always do things exactly when we want to do things.

Barbara: We look for the right time.

Mona and Lisa also talked about the need for collaborative planning and preparation that allows time for both sides. They said,

Mona: I think you're a really prepared woman, you know! I like working with you 'cos it's not rush, rush, rush. Yeah, you really got that time, you know, how can I put it? You really look at the timeline "oh this is best".

Lisa: Yeah and l've tried hard to think about the timeline both that I have to fit in with... but not just from my side, also thinking "what's going to be the right timeline for the people that l'm working with?"

Mona: Mmmm, awa (yes), and then I need to get organised with family as well, you know and it's really good, I still have that email or that phone call in mind all the time and I think "oh I need to get organised for these kids, when I'm going, who's gonna look after them", you know.

Allowing this kind of time for conversation and readiness felt more informed, and more like genuine consent. It also ensured that the narratives that came from that process emerged comfortably and confidently. Interestingly, Mona also talked about the timing for her being right in a much broader sense. She talked about feeling like the time was right in her life and her career to have a story to tell:

Mona: I think it was the right time, yeah. 'Cos l've experienced enough you know, working in the school, and that build-up of the knowledge. I had the knowledge that built up the experience, l've learned through teaching, and I think it was the right time to tell this story. Yeah, the main thing is about my career and how I started and where I am at now, at this point. And I think it was the right time.

Often in university-based research one of the points of stress is the time constraints people have to work under. In this work we actively pushed against that linear sense of time and took a more seasonal approach, paying attention to things such as readiness as an indicator to proceed. The interesting thing about doing it this way was that even though we took quite a long time in the beginning to talk and make sure everyone felt ready and happy to proceed, this meant that other parts of the process happened more quickly and effectively because we were all consensually working together towards the same goal. 


\section{Relationships: We need to be honest, we can't tell each other lies; we can't leave you by yourself}

The pre-existence of relationships in research work is one of the areas that causes a great amount of friction between western ways of knowing and Indigenous ways of knowing. While Indigenous scholars identify careful and meaningful attention to relationships as central to any research conducted with Indigenous participants (Kovach, 2010; Martin, 2008; MoretonRobinson \& Walter, 2009; Wilson, 2009), ethics committees continue to use it as a reason to deny approval. In the ethics approval process for this research Lisa had to apply for ethics clearance from both Charles Darwin University and the Education Department of the Northern Territory. The CDU process had steps built in for Lisa to explain the existence of relationships between herself and the teachers and she was able to gain this clearance, although she was still required to talk about some ethical concerns in this area. The Education Department had its own ethics committee and the committee denied Lisa's application twice on the basis of (amongst other reasons) "the subjectivity of the project as submitted (arising from the sample of participants chosen, the existence of relationships between yourself and the chosen participants)" (NT Department of Education personal correspondence, 14 September, 2013). Kovach (2010, p. 42) addresses this directly, stating that "certain western research paradigms frown upon the relational because of its potential to bias research". She also reminds us that methodologies that come from an Indigenous research paradigm challenge western research paradigms because they "embrace relational assumptions as central to their core epistemologies" (Kovach, 2010, p. 42). Ultimately, the NT Department of Education ethics committee suggested that the research project could be conducted "outside Northern Territory government schools and instead in the community...if the research does not involve the Department's endorsement or resources" (NT Department of Education personal correspondence, 13 December, 2013). This issue was something that Lisa discussed directly with the teachers, as shown in this conversation between Lisa and Fiona:

Lisa: In doing this project you have to go through this process called ethics where you have to think about "are you going to do it in the right way?" One of the things when I was talking to the University about this, they said to me "oh we're a bit worried because you're already friends with all of these ladies". They were worried about that.

\section{Fiona: $M m m$ ?}

Lisa: And I said, "no that's really important I think having those relationships already, because we worked together before and now we're coming back together and doing some more work together, and we're friends in between". I said, "no I think that will help the research not make it harder".

Fiona: $\mathrm{Mm} \mathrm{hmm}$.

Lisa: What do you think about that? What would you think about doing the research, telling this story with me, as opposed to doing it with someone you didn't know?

Fiona: Maybe that someone that you work with if you don't know them very well, he might give you wrong stories and everything. But someone who we've worked with and who has helped us through the study, we've got a lot of things that you can get out for your research. Maybe for this research you might not pass it from working with other people that you don't know. But with us, I think that's really 
good, you got us back together. You helped us do our studies and then got us back to help you. Yuwai (yeah). And I think you should be proud of yourself, you know, happy, because you got the same people back helping you. But if you would have got other people maybe and you wouldn't have known them.

For Fiona it seems that the kind of research that was undertaken relied on the relationships, rather than seeing them as a risk. The greater risk would have been for Lisa to do this research with people she didn't know. Mona and Lisa also talked about how already having that relationship and knowing that we can trust and rely on each other helped us to work together again.

Mona: I think we built that relationship and trust in each other when we were, you know, part of your team, yeah.

Lisa: When we were doing that other work?

Mona: Yeah and it just built up, and that's why.

Lisa: And so does that make it, you more interested in doing this work now, because you already had that experience and because we already had that existing relationship and trust?

Mona: Mmmm, awa, and I can, you know, if I want to do things, like go on to do... you're going to be there, you're going to be helping me, I trust you.

Relational trust was mentioned many times in our conversations about how we worked together. Knowing each other and trusting each other had been a foundation that had built up over time and had helped us all to feel comfortable working together. In reflecting on her own research Kovach (2010) states "the relational factor - that I knew the participants and they knew me - was significant.... With this method the researcher must have a certain amount of credibility and trustworthiness for people to participate in the research. With more trust there is the likelihood of deeper conversations, and consequently the potential for richer insights to the research question" (Kovach, 2010, p. 46). Barbara expands further on this idea that, in knowing each other, it is important to include not only familiarity and feeling comfortable, but also the idea of being able to be honest with each other because of this relationship.

Barbara: I feel very happy to help you with your research because I'm your friend, I want to be part of you, I want to share my knowledge to... all those educational research questions made me think about, you know, I want to do it (the) right way... We need to be honest, we need to be really strong about it. We can't tell each other false or lie. We need to be truth(ful) about it, yuwa (yes) because I can't tell you lies, sorry for you. I need to be honest to you. And how I feel about it it's really good and it's a really strong conversation.

Relationships also guided the process of analysing the data for the research. A conversation between Barbara and Lisa highlighted the importance of collaborative research finding ways for everyone to remain involved throughout the entire process of the research.

Lisa: That's my job to find those important ideas and those important learnings, but I don't want just me to be the one who decides what's important.

Barbara: We've gotta look into it. 
Lisa: Yeah, so that's what I'm asking is for all of you to help me again to work out what are the important ideas.

Barbara: Yuwa, and look for what are the good ideas.

Lisa: Yeah, so it's not just my...me and my ideas.

Barbara: No, we can't leave you by yourself, we gotta use everyone's eyes and ears and search for it.

The idea of not leaving people by themselves is something we came to talk about using the word "marlpa". This is a word used in the Warlpiri, Luritja and Pitjantjatjara languages. It has equivalences in many other Indigenous languages. It is often translated simply as "company" but has many other layers of meaning. At its core marlpa is relational. It is about friendship, doing things together and not leaving anyone out. It is a way of being with others that ensures harmony, connectedness and relational responsibility. Marlpa is often experienced bodily as a "good feeling". It was of central importance to how we worked together in this research process.

Knowledge itself was also seen as relational. Warlpiri scholar, Pawu Kurlpurlurnu (also known as Steve Patrick) reminds us that for Indigenous epistemologies the knowledge lies in the "relationships", not in the "separate parts" (Pawu Kurlpurlurnu, Holmes \& Box, 2008, p. 15). In our conversations this concept is perhaps best demonstrated the following excerpt from Barbara, who said:

Barbara: ...sharing all my experiencing with you, through video, through talking, recording me, I don't feel shy for them now...my history is helping both you and me because that's like our country helps us to do our language and culture, it's like that. History is a good (way) of sharing our stories and, you know, finding out about our history. What l'm trying to say is, it's a key word, a key thing to sit down and talk about it but using that for your PhD. Yuwa (yeah). Ngurrjunyayarni (really good)...in Yapa (Warlpiri) way we don't teach adults we learn from each other, by talking and walking together, sharing together everything. See like we (are) both teaching each other and having (an) educational conversation...I'm getting ideas from you so that I (can) work with Elders (and) adult people. (That) give(s) me experience not to feel shame for that adult person, because I want to show that person that I'm a leader... so that person can learn from me and I want to learn from that person...and it is good so that we leave each other with a happy feeling.

Rose (2004) asserts that relationships are crucial to doing effective decolonizing knowledge work because it is through these relationships among people and between people and place that alternatives to the ways we have done things in the past can arise. We need these relationships to derive a new sense of ethics, an "ethic of connection", where we see ourselves as "mutually implicated humans whose primary duty is to respond to the calls of others" (Rose, 2004, p. 14). Rose calls this an ethics of responsibility, not guilt, an ethic that "demarcates a path towards decolonization...towards a human condition of living with and for others" (Rose, 2004, p. 12). Relationships provoke us to be vulnerable and responsive in our knowledge work and to honour our connection to each other above all other outcomes. 


\section{Reciprocity: You helped me so I have to help you}

In considering ethical consent around this research project, especially with work that was built on the foundation of pre-existing relationships, we had to explore on a regular basis the motivations of why people said yes to participating. Lisa was really concerned that she didn't want to people just to say yes to being part of the project because they were friends with her. What she had to learn was that reciprocity is an important part of working together. The connection to the previous work we had done together was a really strong reason why people wanted to keep going with this work. People saw it as a continuation and in many ways a reciprocation. For example in the group conversation that happened in 2013 the following exchange took place.

Barbara: Alright well Pitjan (Lisa) you helped us get through upgrading, now we gonna all help you.

Yamurna: Yuwayi (yes).

Lisa: Thank you.

Mona: Yeah.

Barbara: Help you get through your PhD, we're your family.

Lisa: Thank you and I like that, this what I call reciprocity.

Linda: Owa, palya ngapartji ngapartji (yes, that's good, giving back).

This feeling of reciprocity or "ngapartji ngapartji", from the Luritja and Pitjantjatjara languages meaning "you give something to me and I give something to you", continued to be spoken about as the research work went on. In a conversation with Lisa, Fiona said,

Fiona: I really wanted to help you...I can't let you down because you helped me through my study and I have to help you pass your PhD...I would always help you in anything to pass your research or any other work that we can do. Yuwai (yes) I'm really happy to do that to help you out you know. Yuwai (yeah).

A conversation between Mona and Lisa also illuminated the current work as something that was seen as part of an ongoing reciprocal relationship, not just with the past, but also into the future:

Mona: And like some of us are like looking at doing Masters, and you know that'll really help decide.

Lisa: And that's the other thing, if as part of this I can help you with something, you know you're helping me with something, if I can help you achieve something that you want to do then that would make me happy to, that if we can give something for each other, that would be a really good outcome I think.

Mona: $M m m m$, awa (yes), and I can you know, if I want to do things, like go on to do (more study) you're going to be there, you're going to be helping me, I trust you. 
Lisa: Yeah, so for other things.

Mona: Other things, awa (yes).

Lisa: Yeah that's interesting you going back to study and me being able to help you with that, Linda applying for another job and me helping her with that..." reciprocity" so you helping me with my study, me helping you out with things that you need and I feel like there's a kind of, you know, sharing there, that we can help each other out with things, which I like as well.

Mona: Yeah.

Lisa: You know just little things that I can do that make like easier for people, help them out when they need help, but you know there's what I call that reciprocity, helping each other.

Mona: And that's important, that's very important.

But this concept of reciprocity went much deeper than a simple exchange of favours or assistance. In many ways what people were feeling was a sense of reciprocity with learning and sharing itself. Linda saw part of her participation in the work as a reciprocal obligation to ensure that Lisa learned things as well while they were working together. This in a way became a reciprocity of knowledge systems as enacted by people.

Linda: Yuwa (yes), and that's what I like, you know, working and trusting and getting something from the learning process, yuwa (yeah).

Lisa: I feel really happy about the fact that during the times when I've been here at Papunya, you've taken me out to some places...so it hasn't just been about us sitting and doing the research together, those times of recording and work.

Linda: Visiting country and meeting other people palya (good).

Lisa: Yeah, and so it's not just about you and me but about this whole community that you're part of and like those women that we went digging with yesterday and the kids and understanding, yeah I guess, you're helping me to see the connections between all those things, which I'm really grateful for, that's been really enjoyable for me too to get to know that part of...

Linda: Yuwa palya lingku (yeah, really good).

It also became clear that the act of telling a story provides a sense of wellbeing for the teller. A number of our conversations raised how good it felt to tell the story and how it brought about a feeling of pride and happiness to have told the story and had it recorded, valued and preserved. This exchange between Linda and Lisa is a good example of this feeling:

Linda: I've been learning so much and in that journey l've learned so much. I didn't learn you know, enough at school but l've learned so much (since)... And there was good principals and bad principals, good staff and bad staff, but I hung in there and learned so much that and...l'm not telling someone's story, it's my story that's from those experiences that I had, it has to be told and l've told that, yuwa (yeah). 
Lisa: So you're feeling good about...

Linda: Yuwa (yes)... having a chance to tell that...'cos sometimes (it) can be hidden and that's when people are, you know, not ready to tell what they've experienced and it makes me feel palya (good) about it, that l've told my story.

Mona also expressed a similar feeling at the end of her narrative recording:

Mona: I think you know, I think this is the best part...yeah you know telling someone my story. I think I feel good 'cos I don't often tell people stories, yeah and I think this was a good way, a good way of telling my story, my journey, yeah and it makes me feel good...'cos often I don't talk...you know...talking about your life in normal talk. You can't go into that. But I think I feel good 'cos I've talked to you and I've told this story of my journey. I really wanted...someone to come up with it and ask me... 'cos I've been trying really hard to get this out...someone to come and tell me, 'oh can you tell me about your journey?' But it was really good I had the chance to do it.

Similarly when asked how she felt about having told her story Fiona said,

Fiona: I feel really proud of myself, like what l've experienced in my teaching days, yeah really good you know, from when I started first year of my study and when I started teaching under those tress you know, to the building, silver bullet and all that. And then teaching my own classes... and it's good... when you're doing that research with the others, you can tell them. Because we came from the bean tree, not from the building. Because what they're gonna see from Yuendumu mob...they started in the building, but not us, we started under the bean trees. Next to the sand dunes. Yuwai (yes), see that's different, unga (isn't it)?

This feeling of wellbeing that came from telling these stories also extends to the feeling of doing something that will help future generations. In this sense reciprocity becomes about a relationship with the future and the obligational responsibility to pass knowledge on. Yamurna talked about this idea:

Yamurna: I think it's good to talk about my things that we done long time (ago), you know, yuwayi (yes)...I just want you to keep this story so maybe when I pass away so my grandkids can see it, you know. And they (will) read it you know, so they can become teachers in the future... They don't have to be teacher maybe they could be nurse or work in an office? Yeah, and they'll be thinking of me...it's really good to share my story... when I started young, now l'm getting older and older, and long time when people were in school...I didn't used to teach, I was shy. But now I can teach.

Fiona also saw her story as something that she was doing to support future generations in her community. She also had ideas about ways to disseminate the research that would have currency and meaning for her community,

Fiona: That's what we want to see yuwayi (yes), young people may be looking at our work what we did with you, they might think about it now you know. Maybe in the community or meeting you know we might tell them, "we did this research, helped nampijinpa (Lisa)". I think there's maybe something gonna come out, maybe DVD or something? You know, a book? So we can let the others know you know. Yeah, and I will be like talking about it, sharing if they ask me for ideas you know. Looking at mainly the young ones, young kids, young people if they want to do study, because we want more young teachers, more Yapa (Warlpiri) teachers in the community. 
These final words from Fiona are especially important as it shows that she never lost sight of the original reason for doing the research in the first place. Although there were times in the research where we had to rethink things, cancel plans, find alternatives and realise that something we wanted to do was not going to happen, the flexibility built into the conversational approach (Kovach, 2010) meant that everyone continued on with the research for the entire process. Additionally we remained bound together in the work by our common concern (Addelson, 1994) over the low numbers of Aboriginal people from remote communities becoming qualified teachers, and our "philosophical orientation" (Kovach, 2010) to work together in such a way that we all felt good and our relationships were strengthened by the end of the work.

\section{Conclusion}

Coming together around a common concern was an important part of our relational and ethical research. It provided the reason for doing it and the motivation to stay the course. However, truly relational and ethical research required us to pay attention to our philosophical orientation and to respect and honour the ways that we worked together. It also required us to resist some of the ways that the western academic system tried to push us around. When the western system of research pushed us to hurry and get things done by a deadline, sometimes it was important to push back and slow things down. We needed to allow time for conversation, thinking, asking questions and finding the right time to proceed. When the western system required us to give consent to participating in the process we needed to discover, define and practice what consent looked like and felt like for us. This meant that we had to keep checking in with each other to make sure we were all still happy to keep going with the research. At times when things got hard for people we needed to find ways of being flexible and finding solutions that worked for everyone. Our relationships, which had been established over many years of working together, guided us. There were times when we had to defend these relationships against the criticism of the western academic system that tends to see relationships as a risk when it comes to research. But those relationships helped us to know how to work together, to trust each other and to be honest with each other. That trust also helped us to explore the research questions more deeply and honestly. It was also important to make sure that the outcomes for the university were not the only things that were given priority. We used the spirit of reciprocity to make sure that everyone's needs were being met and that we were helping each other in a balanced way. It was our shared passion for education and concern for the future education of young people in our communities that motivated us to continue and persevere. But good communication, genuine consent, strong relationships and reciprocity helped us to navigate the research space so that in the end everyone was left with a feeling of pride and satisfaction in what we had achieved together. 


\section{References}

Addelson, K. P. (1994). Moral passages: Toward a collectivist moral theory. New York: Routledge.

Hall, L. (2017). Anma, marpla and ngapartji ngapartji: Insights Into how to do research together in "good faith". Learning Communities: International Journal of Learning in Social Contexts [Special Issue: Decolonising Research Practices], 22, 70-80. DOI: https://doi.org/10.18793/LCJ2017.22.07

Hall, L. (2016). Moving deeper into difference - developing meaningful and effective pathways into teacher education for Indigenous adults from remote communities. (Doctoral dissertation, Charles Darwin University, 2016). Retrieved from https://espace.cdu.edu.au/eserv/cdu:60314/Thesis_ CDU_60314_Hall_L.pdf

Kovach, M. (2010). Conversational method in Indigenous research. First peoples Child and Family Review, 5(1), 40-48.

Martin, K. L. (2008). Please knock before you enter: Aboriginal regulation of outsiders and the implications for researchers. Teneriffe, Qld: Post Pressed.

Moreton-Robinson, A., \& Walter, M. (2009). Indigenous methodologies in social research. Social Research Methods, 2, 1-18.

Pawu Kurlpurlurnu, W. J., Holmes, M., \& Box, A. (2008). Ngurra-kurlu: A way of working with Warlpiri people. Alice Springs: Desert Knowledge CRC.

Rose, D. B. (2004). Reports from a wild country: Ethics for decolonization. Sydney: University of New South Wales Press.

Thrift, N. (2004). Practising ethics. In M. Pryke, G. Rose \& S. Whatmore (Eds), Using social theory: Thinking through research (pp. 105-120). London: Sage.

Verran, H. (2013). Engagements between disparate knowledge traditions: Toward doing difference generatively and in good faith. In L. Green Contested Ecologies (pp.141-161). South Africa: HRSC Press.

Wilson, S. (2009). Research is ceremony: Indigenous research methods, (illustrated ed.). Black Point, N.S: Fernwood Publications. 